University of Warwick institutional repository: http://go.warwick.ac.uk/wrap This paper is made available online in accordance with publisher policies. Please scroll down to view the document itself. Please refer to the repository record for this item and our policy information available from the repository home page for further information.

To see the final version of this paper please visit the publisher's website. Access to the published version may require a subscription.

Author(s): Edward A. Page

Article Title: Justice Between Generations: Investigating a Sufficientarian Approach

Year of publication: 2007 Link to published version:

http://dx.doi.org/10.1080/17449620600991960

Publisher statement: None 


\title{
Justice Between Generations: Investigating A Sufficientarian Approach
}

\author{
Edward A. Page
}

A key component of global ethics, defined as the systematic study of moral principles and theories that apply to the global realm, concerns the equitable distribution of benefits and burdens across time and space. Until recently, the philosophical literature on global distribution was dominated by the question of how benefits and burdens should be divided amongst contemporaries. Recent years, however, have seen a tremendous increase in research on the scope and content of our obligations to future generations. This has led to a number of innovative attempts to extend principles of distribution beyond the confines of the present generation while retaining a focus on the claims of the existing poor. In this article, I examine a key aspect of intergenerational justice, namely, the appropriate 'pattern' of benefits and burdens that should obtain across generations. With the aid of research into the impacts of global climate change, I compare the merits of rival accounts of the pattern of justice and go on to defend a 'sufficientarian' approach to intergenerational justice, which holds that as many persons as possible should enjoy enough well-being to lead a decent life regardless of when they live.

Keywords: Distributive justice; obligations to future generations; egalitarianism; global climate change

\section{Introduction}

Although the origins of intergenerational justice as a major debate in contemporary ethical theory are multi-faceted, a critical factor has been our increasing awareness and understanding of major environmental threats. Issues such as depletion of the ozone layer, the impact of genetically modified organisms, and, in particular, global climate change, have raised the profile of previously marginal questions such as: do we have duties of justice to protect the environment for future generations? If so, what sorts of duties and how strong are they? Can these obligations ever conflict, and overrule, the duties of justice we have to our contemporaries? Do future generations possess claims of justice against members of earlier generations that specify how income and wealth should be distributed across time and space?

It seems that any comprehensive approach to questions such as the above must address three interlinked, but distinct, ethical problems. The first problem is how to establish the scope of justice. This is the question of which entities (individuals, groups, countries, generations) possess distributive entitlements, as well as the question of which entities bear the duties to guarantee these entitlements are respected. Of particular concern, here, is the issue of whether compatriots living at the same time, contemporaries of all nationalities, or all persons living at all times have distributive claims against others. The second problem concerns the appropriate 'currency' of well-being - such as resources, welfare, or functionings that a theory of distribution adopts in order to concretise the level of entitlement possessed by those identified as subjects of justice (Cohen, 1989; Dworkin, 2000, pp. 11ff; Nussbaum, 2006, pp. 69ff). 
The third problem, which is the focus of this article, concerns the 'pattern of distributive justice (Hurley, 2003, pp.147ff). The issue here is the selection of an appropriate distributive aim that specifies how much of a given currency of wellbeing the subjects of justice are entitled to receive. Thus, it has been suggested that we allocate benefits and burdens so that some currency of well-being is maximised, or shared equally, or so that the worst off group is as well-off as possible, or so that as many people lead a decent life. ${ }^{1}$

The issues of who (scope) should get how much (pattern) of what conception of well-being (currency) are of great importance for our understanding of justice both within and between generations. This is because any comprehensive account of our duties to others, wherever and whenever they live, must give a convincing answer to all three questions to avoid the charge that it is incomplete. In this article, I aim to contribute to the development of intergenerational justice by exploring alternative accounts of the appropriate pattern of intergenerational benefits and burdens. With the aid of examples drawn from research into global climate change, I argue, first, that environmental threats (as well as policies designed to respond to them) are of great significance to discussions of the achievement of all of the familiar approaches to the pattern of justice. Second, I suggest how each of these approaches might be applied to issues of intergenerational distribution. Third, I explore the particular merits of the 'sufficientarian' approach to intergenerational justice, according to which benefits and burdens should be distributed so that as many persons as possible enjoy decent lives regardless of when they live.

It is important to note that, in order to focus as much as possible on alternative theories of the pattern (rather than the scope) of justice, the discussion proceeds from the universalist assumption that future persons, at least in principle, possess valid claims on social goods. I also assume that it is meaningful to investigate the intergenerational application of theories of the pattern of justice in relative isolation of the question of the currency of justice. In this vein, I refer throughout to a general notion of 'well-being' when it is necessary to refer to the unit in terms of which distributive entitlements should be determined. Finally, I focus in the following on undeserved disadvantages, such as inequalities or absolute disadvantages that are beyond the control of those they affect, and put to one side the problem of deserved disadvantages, such as those that result from an agent's autonomous choices.

\section{Justice As Equality}

Perhaps the simplest theory of the pattern of justice is that benefits and burdens should be distributed across some population so that inequality is minimised. We might call this view 'intrinsic egalitarianism' because it holds that inequality is bad or unjust (I use these terms interchangeably) in itself and not because of its consequences. As Temkin has put it, the essence of intrinsic equality is that 'it is bad for some to be worse off than others through no fault of their own' (Temkin, 2003, p.62).

It is worth contrasting intrinsic equality with some closely associated views. Utilitarians, for example, hold that acts and social policies should be evaluated 
only in terms of their consequences, and that these consequences in turn ought to be maximally beneficial in the sense that they promote the maximum amount of welfare possible (Sen and Williams, 1982, pp.3ff). Depending on the circumstances, the utilitarian may prefer an equal distribution of well-being because this coincides with the desire to maximise welfare. The reason for this is that it is generally easier to help the worse off than others - one only has to give them a little for their welfare level to improve a lot. In this sense, utilitarians are 'accidental', rather than intrinsic, egalitarians.

There are other 'accidental egalitarian' theories of distribution that are more persuasive than utilitarinaism. Some of these are motivated by the somewhat paradoxical feature of intrinsic egalitarianism that it aims to reduce, or avoid, inequalities even when this does not benefit the worst off or most needy. The distinction between reducing inequality and giving priority to the worst off, for example, has been explored Derek Parfit in terms of a further clarification of intrinsic egalitarianism. In his influential 1995 Lindley Lecture, entitled 'Equality or Priority?', Parfit argued that intrinsic egalitarianism can be divided into two groups: those that assume that inequality is always in itself bad ('telic egalitarians') and those that assume that inequality is bad only if it has certain origins ('deontic egalitarians') (Parfit, 1995, pp.3ff). There are a number of differences between these two views. One is that they diverge on the issue of the amount of inequality and the badness of the inequality of a distributive outcome. Thus, the telic view assumes that the more inequality that exists the worse the outcome. On the deontic view, however, one can have more inequality, but this might not mean we have a worse outcome. It all depends on how this inequality came about.

Parfit went on to show that endorsing either version of intrinsic egalitarianism has important consequences. One of these concerned the way in which applying egalitarianism could have counter-intuitive implications in certain circumstances. Consider a version of what has become known as the 'levelling down problem' (Parfit, 1995, pp.17ff). Here, half of some population are rich and enjoy a high level of well-being, while the other half is impoverished and enjoy a much lower level of well-being. Other things being equal, intrinsic egalitarianism would view a move to an entirely impoverished population in such cases as just in at least one respect, a view that many have regarded as absurd (Raz, 1986, pp. 230-5; Nagel, 1979, pp. 106-122). The Levelling Down Problem suggests that we must either reject the view that it is just in one respect to bring some down to the level of others even if no one benefits, or reject the view that inequality is in itself unjust.

While the levelling down problem seems to apply to all formulations of the telic view, it does not seem to plague the obvious interpretations of the deontic view. The latter condemns outcomes only if they arise from actions that involved wrongdoing. The well-off in the above example might, for example, be viewed as entirely innocent of the misfortune of their less well-off compatriots, so the inequality between these groups may not be regrettable from the deontic egalitarian point of view. Nevertheless, in theory, the deontic view will require that we level down for the sake of no one if it was the product of wrongdoing. This is an important observation, for some egalitarians have argued that much of 
the global inequality that exists today, and which will persist into the future, has origins in the past and present wrongdoing of individuals and institutions in rich populations (Pogge, 2005, pp. 92ff). Although highly controversial, this claim, if defensible, would reduce significantly the number of occasions where the deontic view would have alternative implications to the telic view. That is, where it is possible to redistribute the resources to restore equality, it would be just to level down for the benefit of no one.

The levelling down problem can be reformulated to cover dealings between different generations. Suppose that, following the work of economic growth enthusiasts such as Wilfrid Beckerman and Bjørn Lomborg, almost all persons living in future generations will be better off than their predecessors, despite the environmental and social problems the former are set to inherit (Lomborg, 2001, pp. 327-52; Beckerman and Pasek, 2001, pp. 50ff). According to the telic view, it would be better in one respect if the present generation consume a certain amount of resources so that our descendants will not be any better off than us. That is, present persons would be some moral pressure to develop unsustainably since sustainable development, on all of its formulations, involves the creation of intergenerational inequality. According to the deontic view, this pressure is removed since it does not seem plausible to argue that the intergenerational inequality brought about by the sacrifices of earlier generations to save for the benefit of their successors involves wrongdoing.

Because it rests on our intuitions about the relative inequality of unequal and equal outcomes, and the examples discussed here are rather abstract, it is not obvious how intrinsic egalitarians should respond to the levelling down problem. Some, such as Larry Temkin, have argued that the problem is illusory. Temkin holds that the levelling down problem merely shows us a consequence of egalitarianism, not a reason to reject it. Given that we believe in a number of ideals, Temkin's thought is that levelled down outcomes are always desirable 'in one respect' even though they may be undesirable 'all things considered' (Temkin, 2003, pp.68ff). Temkin's uncompromising defence of telic egalitarianism raises a number of interesting questions about the nature of distributive justice, as well as the appropriate methodology adopted to analyse it. To some, Temkin is merely attempting to defend the indefensible (Crisp, 2003, pp. 758ff). The problem is that there is no obvious methodological procedure to separate an 'absurd' view from a view that is cogent but has yet to develop strong intuitive support.

Recall that a different response to rescue intrinsic egalitarianism from the levelling down problem is to appeal to deontic egalitarianism. The problem with this appeal, which adds force to Parfit's critique of intrinsic egalitarianism as a whole, is that it cannot explain what is unjust about inequalities between individuals or groups that do not engage, or have not in the past engaged, in dealings of moral reciprocity. Suppose two populations A and B exist, but have little or no mutual dealings. One day a member of the A population decides to visit population B out of curiosity, and finds to their surprise that the people in B are very badly off compared with those in A, although well-being in both populations is evenly distributed. On the telic view, the inequality evident 
between A and B is regrettable (and all things being equal, should be removed as a matter of justice) even if it was not brought about by wrongdoing. It makes no difference, here, that the inequality arose between those that have hitherto had no mutual dealings. The deontic egalitarian, on the other hand, will regard such inequalities as trivial from the point of view of justice since the inequality did not arise from wrongdoing. Let us call this the 'blameless inequality' problem.

Granted that the deontic egalitarian might recognise other non justice-based reasons to remove the inequality between $\mathrm{A}$ and $\mathrm{B}$, such as compassion or charity, this approach does not seem to be a plausible rendering of either egalitarianism, or distributive justice in more general terms. The dubious global implications of deontic egalitarianism can be shown by reflecting on the following simple thought experiment. $^{2}$ Suppose it transpired, as the first wave of climate sceptics maintained, that global climate change is a very real phenomenon, but has entirely natural, rather than anthropogenic, origins (Singer, 2000, pp. 1-78). ${ }^{3}$ Such a revelation would not affect the fundamental message of a host of climate impact analyses, which indicate that climate change will be generally, if not uniformly, adverse for millions of existing and future persons (McMichael and Githeko, 2001, pp. 451-85; Schellnhuber et al, 2006, pp. 133-202). Deontic egalitarians would have us believe that efforts to mitigate inequalities caused, or exacerbated, by climate change would be beyond the call of justice since they could not be traced to wrongdoing. The telic view, by contrast, would recommend that the inequalities caused by climate change be rectified even if no human culprit can be found.

To conclude this section, it seems that both telic egalitarianism (in condoning levelling down for the benefit of no one) and deontic egalitarianism (in leaving the unlucky victims of blameless inequality to fend for themselves) are flawed understandings of the pattern of justice.

\section{Justice As Priority}

One way in which those broadly sympathetic to egalitarianism might avoid the levelling down, and blameless inequality, problems would be to embrace the ideal of priority, according to which the worse off people are the more it matters from the point of view of justice that they be benefited. Parfit calls this the 'Priority View', and those holding it 'prioritarians' (Parfit, 1995, pp. 19ff.). Prioritarians reject the basis of both telic and deontic egalitarianism, namely, that it is bad that some people are worse off than others through no fault of their own. This is because they are unconcerned with the comparative properties of distributive outcomes. Instead, they think it regrettable that people are badly off as such, and the lower the level of a person's well-being the stronger our duty is to help them. Parfit writes that:

benefits to the worst off matter more, but that is only because these people are at a lower absolute level. It is irrelevant that these people are worse off than others. Benefits to them would matter just as much even if there were no others who were better off (Parfit, 1995, p.23).

Similarly, Arneson defines prioritarianism as the view that: 
It is morally more urgent (gains more moral value) to obtain a oneunit well-being gain for a person, the lower the person's lifetime wellbeing otherwise would be (Arneson, 2006, p.19).

Consider the following example, which concerns choices between competing social policies that alter the distribution of well-being within a hypothetical population. For simplicity, I assume that the policy choices discussed, although they may alter the amount and distribution of well-being, will not alter the population size. The alternative distributions of well-being reflect the possible outcomes of two broad policy 'programmes' that policy-makers can select, each being associated with three specific 'environmental policies.'

\section{Distribution 1}

(1) all at 50

(2) half at 40 , half at 70

(3) half at 20 , half at 80

\section{Distribution 2}
(1) half at 49 , half at 46
(2) half at 55, half at 45
(3) all at 40

In the case of Distribution 1, the requirements of equality and priority converge. Other things being equal, they guide us to choose policy option (1), either because all are equal with respect to well-being; or that the worst off are better off under (1) than they are under (2) and (3). However, in the case of Distribution 2, the equality and priority views do not converge since inequality exists in outcomes (1) and (2) that does not exist in (3), and the worst off are better off in outcome (1) than they are in (2) or (3). Utilitarianism, by contrast, will favour (2) in both cases since this is the outcome where well-being is maximised. Although the Distribution 1 example is constructed at an abstract level, it tells us that, while they often converge in their distributive recommendations, egalitarianism and prioritarianism and utilitarianism are rival approaches to the pattern of justice.

The distinction between equality and priority is of clear relevance to the construction of theories of intergenerational justice. First, environmental threats such as global climate change pose different sorts of challenge to egalitarianism and prioritarianism when they are applied across time. Second, the aims of equality and priority can diverge at both the practical and the theoretical level in what they require of us in relation to our successors.

Regarding the first issue, it seems that major environmental threats such as climate change are highly relevant for any practical application of the priority view since they will influence the absolute well-being of all in the future. There is a wide consensus amongst climatologists that climate changes, such as sea-level rises and extreme weather events, will influence which regions, and populations, of the world will be worst off in the future and to what extent. One specific example is that increased frequency and severity of coastal flooding will degrade the food and water security of millions in coastal zones and small islands (Nurse and Sem, 2001, pp. 854f; Schellnhuber et al, 2006, pp. 167-85). This will 
exacerbate any existing inequalities between coastal and non-coastal populations, but it will also mean that many more persons will be forced to live in absolute poverty.

Climate change can also be expected to help determine which generations will be most disadvantaged in the future. One problem here concerns 'low probability, high impact' events. These are global climate events caused by the emergence of climate processes that have already been witnessed since the evolution of the species. One example concerns the cessation, or re-positioning, of the thermohaline circulation process that transports heat throughout the globe through movements of surface and deep-sea water. Such an event would have massive social, economic and health impacts on populations residing in Europe and North America, potentially triggering global crisis (Schellnhuber et al, 2006, pp. 37-63). While there are huge problems in quantifying the probability of such events occurring, the threat they pose to human well-being in terms of uncertainty and risk alone warrant their being factored into debates concerning distributive justice.

Turning to the second issue, suppose that the populations experiencing different levels of well-being each belonged to a different time-period where the lives of their members do not overlap. Suppose, next, that the differential prospects of the populations in the Distribution 2 example arise as a consequence of the different environmental policy choices adopted by previous generations (the population halves representing the earlier and the later generation respectively). For simplicity, we might say that policy (1) equates to a moderate conservation stance, policy (2) to no conservation at all, and policy (3) to a radical conservationist stance, which could sustain the same well-being levels indefinitely but at a lower level than either of the other less sustainable policies:

\begin{tabular}{|c|c|c|}
\hline & GENERATION 1 & GENERATION 2 \\
\hline POLICY 1 & 49 & 46 \\
\hline POLICY 2 & 55 & 45 \\
\hline POLICY 3 & 40 & 40 \\
\hline
\end{tabular}

In this simple, two-generation model, intergenerational egalitarians would have at least some reason to prefer (3). That is, they would have an egalitarian objection to the other two divisions that does not arise with this distribution. Utilitarians, on the other hand, would favour (2) since it maximises total well-being across both generations. Finally, prioritarians would favour (1) as the worst off population is better off under this policy than the alternatives. The picture would change as we include further populations from different time-periods, but this example supports the conclusion that which pattern of justice we prefer will shape our approach to both intergenerational and intergenerational distribution. 


\section{JUSTICE AS SUFFICIENCY?}

To sum up the discussion so far, prioritarianism is a demanding approach to distributive justice that welcomes inequality if it is of benefit to the worst off. It is not subject to the 'levelling down' or 'blameless inequality' problems since it is a non-comparative view that ignores the origins of the pattern of any given distribution. Finally, it recommends alternative distributions of well-being across generations to its egalitarian rival in at least some circumstances.

In contrast to egalitarians and prioritarians, some theorists, such as Harry Frankfurt, hold that benefits and burdens should be distributed in line with the 'doctrine of sufficiency.' This states that as many people as possible should have enough (of the currency of justice adopted) to pursue the aims and aspirations they care about over a whole life; and that this aim has lexical priority over other ideals of justice, such as equality, priority, or utility (Frankfurt, 1987, pp. 21-43; Frankfurt, 1997, pp. 3-14).

Attaining what we really care about, for Frankfurt, requires a certain level of wellbeing, but once this level is reached there is no further relationship between how well-off a person is and whether they discover and fulfil what it is that they really care about. Frankfurt holds that, above the level of sufficiency, it is neither reasonable to seek a higher standard of living nor expect as a matter of justice any additional allocation of some currency of justice. It is important to add that 'having enough' is not the same as living a 'tolerable' life in the sense that one does not regret one's existence. Rather it means a person leads a life that contains no substantial dissatisfaction.

Sufficientarianism will often converge with the distributive aims of prioritarianism and egalitarianism. All persons should be helped to the threshold of suffiency if possible, and those who can be helped to lead a decent life are often among the worst off in a population. But the aim of reducing inequality, or of improving the position of the worst off, has no intrinsic value for sufficientarians and will be sacrificed if and when they conflict with the doctrine of sufficiency.

According to Frankfurt, the flaw in intrinsic egalitarianism 'lies in supposing that it is morally important whether one person has less than another regardless of how much either of them has' (Frankfurt, 1987, p.34). What matters, Frankfurt argues, 'is not that everyone should have the same but that each should have enough. If everyone had enough it would be of no moral consequence whether some had more than others' (Frankfurt, 1987, p.21, original emphasis). This does not mean, however, that a concern to equalise well-being will always frustrate sufficiency. Recall the case of Distribution 1:
(1) all at 50
(2) half at 40 , half at 70
(3) half at 20 , half at 80

Suppose that advances in the human and natural sciences furnished us with an account of the level of well-being at which point a person has 'enough', and that 
this turned out to be 50 units of some agreed currency of well-being. Equality, priority, and sufficiency would in such circumstances converge on recommending the same distribution: (1). In such circumstances, Frankfurt observes, 'even if equality is not as such morally important, a commitment to an egalitarian social policy may be indispensable to promoting the enjoyment of significant goods besides equality or to avoiding their impairment' (Frankfurt, 1987, p.22).

The differences between equality, priority and sufficiency becomes clear when reconsider Distribution 2. Recall that the outcomes here were the following:
(1) half at 49 , half at 46
(2) half at 55, half at 45
(3) all at 40

Suppose, again, that the sufficiency level for all was 50. Whereas intrinsic egalitarianism seems, other things being equal, to favour outcome (3) and prioritarianism would favour allocation (1), sufficientarianism would favour outcome (2) since this would be the only outcome in which at least some people had enough. For the sufficientarian, the distribution of benefits and burdens to achieve equality or priority in such cases is indefensible. It would be analogous to the tragedy involved in a famine situation of giving food to those who cannot possibly survive at the cost of those that could survive if they received extra rations. In this sense, the ideal of sufficiency is related to the medical concept of 'triage', according to which, when faced with more people requiring care than can be treated, medical resources should be rationed so that the most needy receive attention first. However, because the category of 'most needy' is defined in terms of the overarching aim that as many people as possible should survive a given emergency, triage protocols often lead to the very worst off being denied treatment in disaster situations in favour of those who can be helped to survive.

Frankfurt's view is that all distributive claims arise in some way from an analysis of where people stand relative to the threshold of sufficiency, or as he puts it the 'threshold that separates lives that are good from lives that are not good' (Frankfurt, 1997, p.6). Egalitarianism, by contrast, posits a relationship between the urgency of a person's claims and their comparative well-being without reference to the level at which they would have enough. Since allocating people enough to lead decent lives exhausts our duties of distribution, sufficientarians argue that egalitarianism recognises duties that do not exist. In fact, in linking ethical obligations to the comparative fortunes of people, egalitarianism encourages envy and thereby contributes 'to the moral disorientation and shallowness of our time' (Frankfurt, 1987, pp. 22-3). In short, by encouraging the better off to pity the worse off, and the worse off to resent the better off, egalitarianism encourages complacency and arrogance in some and a lack of selfesteem and respect in others.

Although Frankfurt focuses his critique of rival distributive views on intrinsic egalitarianism, it can be readily extended to cover prioritarianism. While the priority view is grounded in the badness of absolute rather than comparative disadvantage, it is also inclined to divert resources to the worst off group even if this would mean sacrificing substantial benefits to other, slightly better off, 
persons who could be helped to lead a decent life. Frankfurt argues that, 'It is true that people in the lowest strata of society generally live in horrible conditions, but this association of low social position and dreadful quality of life is entirely contingent. There is no necessary connection between being at the bottom of society and being poor in the sense in which poverty is a serious and morally objectionable barrier to life' (Frankfurt, 1997, p.2). The problem with prioritarianism, then, is not that it fetishises comparative well-being but rather that it fetishises absolute well-being with the result that mandates constant interference in people's lives to benefit the worst off. By doing so, prioritarianism is inclined to generate the same sorts of envy and pity as its egalitarian rival, and recommend a huge range of redistributions that do not help their recipients to lead decent lives.

Consider the following example. There are two groups in society, where one enjoys a considerably lower level of well-being than the other, where both groups enjoy a far better than sufficient life, and where the inequalities are undeserved. We can call these groups the 'very happy' and the 'extremely happy.' Egalitarians claim that, if we could do something about it, the very happy group should be compensated for their relative well-being deficit. This is because this theory regards undeserved inequality as bad even if everyone is at least very happy; that is, it makes no ethical difference that the inequality is between groups, or persons, who are very well off. Sufficientarians, by contrast, holds that there is no case at all to redistribute in a world of very happy and extremely happy since this will not bring it about that anyone who did not have enough before will have enough after redistribution. Finally, Prioritarians regard the very happy in isolation of their relative happiness as they are only interested in absolute levels of well-being. Nonetheless, the very happy, as the worst off, deserve the attention of prioritarians even if they live so well they want for nothing. If we are able to help them become better off, that is, it would be unjust not to do so. According to sufficientarians, such a claim is absurd. How can there be a duty to help the 'worst off', they ask, when this group lead lives of such a high standard already?

\section{CLIMATE CHANGE, POSTERITY, AND THE DOCTRINE OF SUFFICIENCY}

We have seen that ideals of equality, priority and sufficiency often converge in the pattern of benefits they recommend. However, conflicts between these ideals emerge both in theory, and in practice, since the composition of the worst off group, comparative fortunes, and people's positions relative to the sufficiency threshold diverge in various hypothetical examples, as well as in real life. So, even if all three ideals are global in the sense that they specify entitlements to all persons living in all times and places, it can be of great relevance which of these ideals we adopt. In this section, I explore in more detail the benefits of a adopting a sufficientarian approach to questions of intergenerational distributive justice.

Consider the impact of climate change on three particularly important dimensions of human well-being: health, water quality and security and economic wealth. All human beings require a certain level of health to pursue whatever it is they really care about, even if there are limits to the level of general health and nutrition that 
is necessary for people to have enough to pursue their life plans. This is reflected in the broad consensus amongst philosophers that physical and mental health is essential to the functioning of all persons, regardless of their life-plans or social context (Nussbaum, 2006, pp. 76-7; Doyal and Gough, 1991, pp. 49ff; Copp, 1998, pp. 123ff). A key finding of the IPCC Third Assessment Report of 2001 was that the cumulative impacts of climate change on future human health will be, on balance, extensive and adverse (McMichael and Githeko, 2001, pp. 451ff). The World Health Organisation similarly reports that climate change will result in many thousands, possibly millions, of people dying who otherwise would not have died, for example through exposure to extreme heat events, droughts, floods, and changes in infectious disease transmission (McMichael et al., 2003, pp. 4360 ). It seems clear that the health impacts of climate change will prevent many future people from leading lives of a decent quality, as well as exacerbating inequality and jeopardising the fortunes of the worst off. The same will be true of water security and socio-economic impacts.

The sufficiency view has attracted considerable support in environmental circles in the guise of the pre-eminent understanding of sustainable development. According to this, development should meet 'the needs of the present generation without compromising the ability of future generations to meet their own needs' (World Commission on Environment and Development, 1987, p. 43). Although the source of great debate and controversy, the core idea is that each generation (considered as a mere aggregate of individuals or more distinctively as a collective in its own right) should refrain from activities that leave later generations without enough, but that this does not mean that an injustice is committed if the latter are prevented from enjoying an exactly similar, or improved, level of well-being. As such, the sufficiency version of sustainable development will result in a different set of requirements than alternative constructions based on priority or equality. Examples of rival constructions are that: 'each generation is entitled to inherit a planet and cultural resource base at least as good as that of previous generations' (Arrow et al, 1996, p.15n) or that 'welfare per head of the population must never decline' (Beckerman, 1999, p.72) or that we should 'be concerned with preserving - and where possible expanding the substantive freedoms of people today without compromising the ability of future generations to have similar, or more, freedoms' (Sen, 2004, p.1).

The exact requirements of sufficientarianism will depend on the distributive context, as well as the specification of the threshold of sufficiency itself, which will be framed in terms of the best scientific evidence available and modified by public deliberation about what constitutes 'having enough' and 'dangerous climate change.' We can assume, however, that a sufficientarian approach would involve stringent action to stabilise, and later reduce, concentrations of greenhouse gases in the atmosphere (to minimise the number of lives that are forced under the sufficiency threshold by climate changes that are still preventable) and major international investments in terms of measures and technologies of adaptation (to maximise the number of lives lived at or above the threshold in the face of climate impacts that are no longer avoidable). 
Aside from working towards a global (and stringent) climate accord to replace the current Kyoto Protocol when it expires in 2012, there are numerous smaller scale measures of mitigation and adaptation available to the present generation to fulfil the requirements of intergenerational sufficiency. Energy efficiency could be increased to reduce global greenhouse gas emissions in both the industrial and domestic sectors; transport practices could be altered; and more efficient land management practices could be adopted (Markandya and Halsnaes, 2001, pp. 474ff). Meanwhile, water security could be enhanced in developed and developing countries by improving flood defences; human health impacts could be minimized by improved public health infrastructure in communities vulnerable to extreme weather events; and the socio-economic infrastructure of vulnerable populations could be protected by improved planning. In each case, the idea is that earlier generations are bound by a sufficientarian duty to ensure that their successors have access to a climate system that is hospitable for decent human lives.

Perhaps the central difficulty with the doctrine of intergenerational sufficiency is that the distributions it recommends are so sensitive to initial distributions of wellbeing. Consider the following three background scenarios where very many persons currently lie below the point where they have enough (set as 100 units of well-being). In a 'radical insufficiency' situation, we can help all above the threshold, although this would also involve creating large inequalities. In a 'triage insufficiency' situation, we can help some, but not all, to reach the sufficiency threshold although this would involve creating large inequalities and would not help the situation of the worst off. In a 'hopeless insufficiency' situation, we can improve the situation of many people, but not so that any of these people will thereby lead decent lives.

\begin{tabular}{|l|l|l|}
\hline & $\begin{array}{l}\text { BEFORE } \\
\text { REDISTRIBUTION }\end{array}$ & $\begin{array}{l}\text { AFTER } \\
\text { REDISTRIBITION }\end{array}$ \\
\hline $\begin{array}{l}\text { TRIAGE } \\
\text { INSUFFICIENCY }\end{array}$ & ALL AT 75 & $\begin{array}{l}\text { HALF AT 50, HALF } \\
\text { AT 100 }\end{array}$ \\
\hline $\begin{array}{l}\text { RADICAL } \\
\text { INSUFFICIENCY }\end{array}$ & HALF AT 75, HALF AT 150 & $\begin{array}{l}\text { HALF AT 100, HALF } \\
\text { AT 200 }\end{array}$ \\
\hline $\begin{array}{l}\text { HOPELESS } \\
\text { INSUFFICIENCY }\end{array}$ & ALL AT 50 & ALL AT 99 \\
\hline
\end{tabular}

The appeal of the sufficiency in 'triage insufficiency' cases is that its rivals are inclined to condemn interventions that result in half of the population leading a decent life for the sake of ethical goals that seem inconsequential in the circumstances, namely, the minimisation of inequality or the maximisation of the position of the worst off. The attraction of the view in 'radical insufficiency' cases is that, unlike egalitarianism, it can explain what would be unjust about not intervening. The sufficiency view, however, cannot apparently explain why we should intervene in order to improve human well-being in 'hopeless insufficiency' cases despite such interventions being better for many, and worse for no one. 
The sufficientarian has at two clear responses to this problem, one defensive and one offensive. Defensively, it could be objected that it is too much to ask of one theory that it provide an intuitive approach in all possible distributive contexts, merely that it does not require that we bring about distributions which are unjust. People's intuitions about the appropriate pattern of well-being in particular cases, even when purged of obvious biases and prejudices, seem so diversely motivated that no theory of justice will cohere with them all.

Offensively, it could be claimed that sufficientarianism is a genuinely distinctive approach to distributive justice in 'radical insufficiency' and 'triage insufficiency' situations, and 'hopeless insufficiency' situations are rare enough to be put to one side. As we saw above, a number of studies suggest that the lives of existing and future people could be greatly improved through measures of mitigation and adaptation so that the numbers of existing and future lives below sufficiency is minimised. While estimating the future global distribution of well-being is an incredibly difficult enterprise, the vast majority of analyses of equity and development take the view that the situation that best describes global development in 2006 is one of radical, not hopeless, insufficiency (World Bank, 2001, pp. 6ff; World Bank, 2005, pp. 9ff; United Nations, 2005, pp. 23ff). Meanwhile, a different approach would be to argue that the appropriate goal in 'hopeless sufficiency' cases is to bring as many as possible to the point where they have the best possible chance of reaching the sufficiency threshold in the future, even if we do not know if this will ever be possible (Copp, 2005, pp.42f).

There are two further issues that need to be addressed before sufficientarianism could be declared as a superior account of the pattern of intergenerational justice. First, we must address the potential counter-intuitions with there being no further issues of justice, or injustice, when all have enough. The problem is obscured when the distributive context involves hundreds of millions of people in our own generation that live in dire circumstances. But it is at least possible to imagine all having enough in the future or at the very least that all who are physically and mentally capable of leading a decent life do so. Can it be the case that there can be no distributive injustice in such situations?

Consider this example (where the sufficiency level has been set at 100):

(1) Half at 150, Half at 200

(2) All at 200

It seems that the doctrine of sufficiency will not distinguish between these scenarios, even though (2) would be preferable to (1) in terms of all rival values. That is, (2) would be much more equal, much better for the worst off, and would create more utility. Can a cogent theory of justice view such gains as trivial from the perspective of justice?

Second, a further problem arises relating to the strength of the priority that sufficientarians give to acts and policies that bring at least some additional 
persons to the point at which they have enough. Consider the following case (where the sufficiency level has again been set at 100):

(3) $99 \%$ of persons at $10,1 \%$ of persons at 100

(4) All persons at 99

Here, the most obvious version of the sufficiency doctrine, which holds that bringing people up to the sufficiency level has lexical priority over other values would require that we opt for distribution (3) over (4) even though this means forgoing great increases in well-being for the vast majority. The problem is that this seems to assign an implausibly great marginal value to the gain in well-being that takes a person from just below to just above the point where they are content (Arneson, 1995, pp. 498-500; Arneson, 2006, pp. 20ff). But why should we weigh this positive change so heavily?

One way of responding to problems such as the above would be to construct a 'pluralist' approach to distributive justice. Pluralism, in this context, means that we would appeal to contrasting ideals in different contexts (Daniels, 1996, p.208). First, the ideals could apply in different distributive circumstances. For example, we might give lexical priority to sufficiency when at least some can be brought up to the threshold, but appeal to equality or priority when all are above, or all below, the threshold (Crisp, 2003, pp. 758ff).

Second, sufficiency might be allocated non-lexical priority over other values so that gains in these other values can sometimes outweigh lesser gains in sufficiency when the former are suitably large or when gains in the former can be achieved without affecting the sufficiency of anyone. Arneson has usefully labelled this 'moderate sufficientaranism' (Arneson, 2006, p.21). The benefit of moderate sufficientaranism, which I cannot pursue in detail here, is that it can explain why we should opt for (2) over (1) since it offers tremendous gains in both equality and priority with no adverse impact on sufficiency. Similarly, though more controversially, moderate sufficientarians have at least some reason to opt for (4) over (3) since equality, priority and utility are far better served by ignoring the sufficiency of the few over the opportunity of giving major benefits to the many.

Third, we might subsume one ideal under another while retaining the idea that the subsumed ideal has some degree of intrinsic, and not merely instrumental, value. Sufficientarians generally view inequality as regrettable because of its consequences, such as the way in which it inhibits economic growth, undermines political processes, or is a malign influence on cultural and social life. Yet, there is a more subtle way that inequality matters. This is that some people might fail reach the standards of a decent life if they are continually faced with the discomfiture that many others are far better off. Similarly, some people might fall below the threshold of sufficiency if they begin to enjoy their life less as a result of identifying with the resentment of others who are visibly much worse off (Marmor, 2003, pp. 127ff). 
I have not the space to develop these intriguing possibilities here. I would like to note, though, that the attractiveness of pluralism as an approach to distributive justice is that different ideals match our intuitions in different contexts. Constructing a defensible theory, however, requires much more than tinkering with different principles, and their weighting, in order to fit with our intuitions. It must also involve a careful consideration of the principles, and the connections between them, that is independent of intuitions about particular examples of their use. To miss this second step out would be to invite the criticism that the new theory is parochial in the sense that it 'merely systematises and renders coherent the particular beliefs of the cultural or ideological group among whose members the practitioner of the method happens to be' (Buchanan et al, 2002, p.372).

\section{Defending A Strict Sufficientarian Approach To Justice}

Allocating sufficiency either 'moderate' or 'lexical' priority over other values presupposes a highly controversial ethical notion. This is that there is a discontinuity in the measurement of personal well-being that separates a life that is decent form one that is not; a life that has enough (of some currency of wellbeing) and one that does not have enough. Yet, what constitutes enough? According to some, the complex issues raised in the last section are of limited relevance for there is no coherent answer to this question. Arneson, for example, writes that:

'A human life can be better or worse for the one who lives it. Wellbeing varies by degree. But it is not so clear that there is a natural way to identify a good enough level, a threshold such that it is of paramount moral importance to get people to the threshold but a matter of relative indifference what happens to them above the threshold' (Arneson, 2006, p. 18).

In this last section, I respond to Arneson's scepticism, firstly, arguing the thought that a threshold of well-being where one has enough is conceptually meaningful and, secondly, sketching briefly how we might establish, substantively, how much is enough for a person by appealing to the notion of basic needs.

The threshold of sufficiency, like other thresholds, is philosophically vague. There will be numerous cases where a person lies just below, or just above, the threshold of a decent life. In such circumstances, it becomes unclear how the sufficiency doctrine applies since we will not be able identify a precise point where additional allocations of well-being to a disadvantaged person transform the statement 'this person has enough' from falsity to truth. The sufficiency threshold, then, bears the hallmarks of a 'Sorites' problem (Williamson, 1994, pp. 11ff).

There are several considerations, however, that point in the direction of accepting a sufficiency threshold, even if it is hard to specify in practice. Some of the most interesting of these reflect the behaviour and attitudes of individual persons. In the strictest sense, drawing any 'poverty line' is arbitrary. There is no answer to the question of why it should not have been drawn slightly above or slightly under the value selected. Yet, it is not arbitrary in the practical sense that people, states, and international institutions habitually make assumptions about the necessary 
features of a decent life. The point, then, is we should ask what assumptions we make in everyday life about well-being and build these into our reasoning about justice. ${ }^{4}$ To put it slightly differently, we focus not on the difficultly of specifying a precise threshold of sufficiency in the face of philosophical vagueness, but rather we ask what practical work a sufficiency threshold can do, for example in the construction of policies to reduce poverty and promote sustainable development.

The above approach might seem a rather ad hoc approach to the grounding of the sufficiency threshold. Yet, it is worth remembering that the attribution of ultimate value to any threshold is problematic for there can be no clear answer to the sceptic who asks why moving a person to within a whisper of any threshold is not trivial form the point of justice, but to move them from this position to just over the threshold is crucial. Take, for example, the very widely used World Bank and United Nations threshold for extreme poverty. This has been set in terms of an income of less than \$1.08 per day, measured in terms of 1993 US\$. In 2005, the UN estimated that roughly 1.1 billion people lived under this 'extreme poverty line', 46\% of which reside in Sub-Saharan Africa and 31\% in South Asia (United Nations, 2005, p. 9). The precise location of the threshold of poverty is, of course, as arbitrary as any threshold of sufficiency, despite being set at a much lower level. Yet, such indicators are extremely useful in the formulation of the goals and targets for of development policy, as well as in the course of academic debates. The first of the UN's Millennium Goals, for example, has the target of reducing by half the proportion of people in the world who have incomes of less than $\$ 1.08$ a day by 2015 (United Nations, 2005, p. xii). In the sense that they are widely understood, and provide practical assistance for the application of moral principles, they are non arbitrary.

Suppose we accepted that, following the practical method suggested above, it was at least conceptually plausible to posit a boundary between a life that has sufficient well-being and a life that has not. A substantive problem remains in identifying where this boundary should be set, that is, we might still ask: sufficient for what? As mentioned above, Frankfurt views 'having enough' as much more than having access to the wherewithal necessary to make life bearable. It should not, then, be thought of as the minimum level at which a person ceases to experience 'extreme poverty' or exceeds some slightly more generous indicator of well-being (such as the UN's threshold of 'mere poverty' of \$2.15 or more a day). Instead, the doctrine of sufficiency relies on a threshold of well-being where a person exhibits no substantial discomfort or distress throughout a life of normal lifespan. So long as all persons who are physically and mentally able have the wherewithal to lead such a life, the duties and entitlements of distributive justice are exhausted.

Although I cannot offer too much precision here, as the threshold will surely vary as it is applied across both space and time, I suggest that a useful way of concretisation the threshold would appeal to the notion of 'basic needs' in a much more explicit way than has been done by sufficientarians such as Frankfurt. Here, we say that a person has enough when all of their basic human needs, generously interpreted, have been met and are likely to continue to be met. The central idea is 
that people must fulfil certain basic needs in order for them to avoid significant harm. As Copp argues, 'matters of basic need are things anyone would require in some quantity and in some form in order to avoid a blighted or harmed life' (Copp, 1998, p. 124; Doyal and Gough, 1991, pp. 39ff; Wiggins, 1987, pp. 14ff).

While there are several ways in which we might unpack this notion of harm, I would argue that the most attractive connects the absence of harm with the capacity to be an autonomous rational agent capable of performing the tasks expected of fully functioning members of society. On this view, basic needs are conceived of 'the things that, at some time in the course of life, are indispensable in some form and quantity to a rational and autonomous life for a human, given the 'laws of nature, unalterable and invariable environmental facts, or facts about human constitution', (Copp, 1998, p.125). The notion of basic need requires further elaboration. For example, it is useful to distinguish between 'basic needs' (such as physical and mental health) and the satisfiers, or 'forms of provision', of these needs (such as income and wealth). The 'satisfiers' of needs will vary according to a person's nature, as well as their historical and cultural circumstances. The basic needs themselves, however, are universal and objective. They are universal, in the sense that the persons living at all times and all places have reason to value the life of a fully functioning member of society, which, for example, exhibits the basic social roles of 'parent, householder, worker, and citizen' (Braybrooke, 1987, p. 48). They are objective in the sense that they are required regardless of whether, and to what extent, they are desired.

Put simply, the approach I am canvassing would seek to enable as many existing and future persons as possible to fulfil, so far as is practically possible, their basic needs over a normal lifetime (Copp, 2001, p. 203). This sketch of what might be called 'global needs sufficientarianism' leaves many questions unanswered. First, it has yet to be established what category of responsibility underwrites the entitlements of justice that the approach specifies. Are they guaranteed by rights, for example?

Second, there is a lingering doubt that the level of well-being associated with meeting one's basic needs is much lower than the level of well-being traditionally associated with the concern of 'having enough' or of 'leading a decent life.' A great deal more work remains to done to unpack these two ideas, as well as what constitutes a 'normal life', a 'normal lifetime', and 'a basic social role.'

Third, there remains the question of how to settle clashes of need both within and between generations. Even in relatively favourable situations, it may not be possible to guarantee the sufficiency of one population without sacrificing the sufficiency of another. When these populations belong to different generations, a peculiarly intractable problem arises of whose sufficiency should take precedence. Whereas some need theorists claim that priority should be given to those who are already in a position to meet their basic needs (Braybrooke, 1987, pp. pp.166ff), others will regard such a temporal bias as morally unacceptable.

Fourth, and finally, there remain unsolved the problems of scope mentioned in the introduction. The literature on ethical needs tends to assume that the bearers of basic needs are individual persons in contrast to the bearers of the duties to fulfil 
them, who are usually viewed as the societies (or states) to which individuals belong. Yet, the peculiar features of intergenerational justice compound the confusion as to the appropriate 'level of analysis' at which duties and responsibilities should operate, just as they do in the context of international justice (Caney, 2005, pp. 754ff). In short, is it individuals, corporations, states, international institutions, or generations as a whole that possess the duties and entitlements of intergenerational distributive justice? Until cogent answers to these questions can be found, the doctrine of sufficiency remains a promising, yet incomplete, approach to global distributive justice.

\section{References}

Arneson, R. (1995) 'Equality', in A Companion to Contemporary Political Philosophy, eds. R.E. Goodin and P. Petit, Blackwell, Oxford, pp. 489-507.

Arneson, R. (2006) 'Distributive Justice and Basic Capability Equality: “Good Enough” is not Good Enough', forthcoming in Capabilities Equality: Basic Issues and Problems, ed. A. Kaufman, Routledge, London (page numbers in the text refer to the public access version of the article available at: http://philosophy2.ucsd.edu/ rarneson/).

Beckerman, W. and Pasek, J. (2001) Justice, Posterity and the Environment, Oxford University Press, Oxford.

Beckerman, W. (1999) 'Sustainability and Intergenerational Equality', in Fairness and Futurity, ed. A. Dobson, Oxford University Press, Oxford, pp. 71-92.

Braybrooke, D. (1987) Meeting Needs, Princeton University Press, Princeton, NJ.

Buchanan, A., Brock, D.W., Daniels, N. and Wikler, D. (2003) From Chance to Choice: Genetics and Justice, Cambridge University Press, Cambridge.

Caney, S. (2005) 'Cosmopolitan Justice, Responsibility, and Global Climate Change', Leiden Journal of International Law, vol. 18, pp. 747-775.

Cohen, G.A. (1989) 'On the Currency of Egalitarian Justice', Ethics, vol. 99, pp. 906-44.

Copp, D. (1998) 'Equality, Justice, and the Basic Needs' in Necessary Goods: Our Responsibilities to meet Others' Needs, ed. G. Brock, Rowman and Littlefield, Oxford, pp. 113-133.

Copp, D. (2001) Morality, Normativity, and Society, Oxford University Press, Oxford.

Copp, D. (2005) 'International Justice and the basic needs principle', in The Political Philosophy of Cosmopolitanism, eds. G. Brock and H. Brighouse, Cambridge University Press, Cambridge, pp. 39-54.

Crisp, R. (2003) ‘Equality, Priority, and Compassion’, Ethics, vol.113, pp. 754-63.

Daniels, N. (1996) Justice and Justification: Reflective Equilibrium in Theory and Practice, Cambridge University Press, Cambridge.

Doyal, L. and Gough, I. (1991) A Theory of Human Need, Macmillan, Basingstoke.

Dworkin, R. (2000) Sovereign Virtue: The Theory and Practice of Equality, Harvard University Press, Cambridge, MA.

Frankfurt, H. (1987) 'Equality as a Moral Ideal', Ethics, vol.98, pp. 21-43.

Frankfurt, H. (1997) 'Equality and Respect', Social Research, vol. 64, pp. 3-13.

Hurley, S.L. (2003) Justice, Luck, and Knowledge, Harvard University Press, Cambridge, MA.

Lomborg, B. (2001) The Skeptical Environmentalist: Measuring the Real State of the World, Cambridge University Press, Cambridge. 
Markandya, A. and Halsnaes, K. (2001), 'Costing Methodologies', in Climate Change 2001: Mitigation, eds. B. Metz, O. Davidson, R. Swart and J. Pan, Cambridge University Press, Cambridge, pp. 451-495.

Marmor, A. (2003) 'Intrinsic Value of Economic Equality', in Rights, Culture and the Law: Themes from the Legal and Political Philosophy of Joseph Raz, eds. L. Meyer, S.L. Paulson, and T.W. Pogge, Oxford University Press, Oxford, pp. 12741.

McMichael, A.J. (1996) 'Human Population Health', in Climate Change 1995: Impacts, Adaptations, and Mitigation of Climate Change, eds. R.T. Watson, R.C. Zinyowera, R.H. Moss and D.J. Dokken, Cambridge University Press), Cambridge, pp. 561-84.

McMichael, A.J., Campbell-Lendum, D.H., Corvalan, C.F., Ebi, K.L., Githeko, A., Scheraga, J.D. and Woodward, A. (2003) Climate Change and Human Health: Risks and Responses, World Health Organization, Geneva.

McMichael, A.J. and Githeko, A. (2001) 'Human Health', in Climate Change 2001: Impacts, Adaptation, and Vulnerability, ed. J.J. McCarthy, Cambridge University Press, Cambridge, pp. 451-85.

Nagel, T. (1979) Mortal Questions, Oxford University Press, New York.

Nozick, R. (1974) Anarchy, State and Utopia, Basic Books, New York.

Nurse, L.A. and Sem, G. (2001) 'Small Island States', in Climate Change 2001: Impacts, Adaptation, and Vulnerability, ed. J.J. McCarthy, Cambridge University Press, Cambridge, pp. 843-75.

Nussbaum, M. (2006) Frontiers of Justice: Disability, Nationality, Species Membership, Harvard University Press, Cambridge, MA.

O’Neill, O. (2000) Bounds of Justice, Cambridge University Press, Cambridge.

Orr, S.W. (2005) 'Sufficiency of Resources and Political Morality', Paper delivered to the Priority in Practice seminar, 22 September 2005, University College London.

Parfit, D. (1995) 'Lindley Lecture: Equality or Priority?', University of Kansas, Kansas City, pp. 1-43.

Pogge, T. (2005) 'A cosmopolitan perspective on the global economic order', in The Political Philosophy of Cosmopolitianism, eds. G. Brock and H. Brighouse, Cambridge University Press, Cambridge, pp 92-109.

Raz, J. (1986) The Morality of Freedom, Clarendon Press, Oxford.

Schellnhuber, H.J., Cramer, W., Nakicenovic, N., Wigley, T. and Yohe, G. (eds) (2006) Avoiding Dangerous Climate Change, Cambridge University Press, Cambridge.

Sen, A. (2004) 'Why we Should Preserve the Spotted Owl', London Review of Books, vol. 26, no.3, pp. 1-5.

Sen, A. and Williams, B. (1982) 'Introduction: Utilitarianism and Beyond', in Utilitarianism and Beyond, eds. A. Sen and B. Williams, Oxford University Press, Oxford, pp. 1-21.

Singer, F. (2000) Hot Talk Cold Science. Global Warming's Unfinished Debate, The Independent Institute, Oakland.

Temkin, L.S. (2003) 'Equality, Priority or What?', Economics and Philosophy, vol.19, pp. 61-87.

United Nations (2005) Investing in Development: A Practical Plan to Achieve the Millennium Development Goals, United Nations, Geneva.

Wiggins, D. (1987) Needs, Values, Truth, Blackwell, Oxford.

Williamson, T. (1994) Vagueness, Routledge, London.

World Bank (2001) World Development Report 2000/2001: Attacking Poverty: Opportunity, Empowerment, and Security, World Bank, New York.

World Bank, (2005) World Development Report 2006: Equity and Development, New York, World Bank. 
World Commission on Environment and Development (1987) Our Common Future, Oxford, Oxford University Press.

${ }^{1}$ It is worth noting that, for some, any society that aims to bring about a certain pattern of benefits in order to realise a moral ideal, such as equality, is itself unjust. For such writers, only 'historical' principles, which explain how resources should be distributed in terms of how they came to be owned and how they were later transferred amongst persons, are consistent with distributive justice. See Robert Nozick, 1974, pp. $153 f f$.

${ }^{2}$ I am grateful to Simon Caney for discussion of this example.

${ }^{3}$ Although the research on which this view was based has been discredited, the fact remains that there have been numerous natural transformations of the Earth's climate over its history. Warmer periods (such as the period between 120 and 90 million years ago) have generally been $5^{\circ} \mathrm{C}-15^{\circ} \mathrm{C}$ warmer than cooler periods (such as the last ice age) and sea levels during these periods are thought to have been at least 150 higher than they are today.

${ }^{4}$ The approach in the text is inspired by the practical approach to the scope of justice proposed by Onora O’Neill in Bounds of Justice (O’Neill, 2000, pp. 192ff). See also Orr, 2005. 